\title{
EFFECT OF THE PILOT CHARGE INJECTION ADVANCE ANGLE ON THE OPERATING PARAMETERS OF A DUAL-FUEL COMPRESSION- IGNITION ENGINE FUELLED WITH BIOGAS
}

\author{
Slawomir Wierzbicki, Michal Śmieja, Andrzej Piętak
}

\author{
University of Warmia and Mazury in Olsztyn \\ slawekw@uwm.edu.pl; smieja@uwm.edu.pl; apietak@uwm.edu.pl
}

Received 2014-06-12, accepted 2014-09-12

\begin{abstract}
One of the ways of increasing the share of renewable fuels in the overall energy balance is to develop effective methods for using low calorific gaseous fuels, including biogas, to fuel combustion engines.

This paper presents the results of research on the effect of changing the diesel fuel pilot charge injection advance angle on the operating parameters of a dual-fuel compression-ignition engine. The obtained results confirm the significant effect of the pilot charge injection advance angle on the engine torque value at a constant engine speed.

Key words: compression ignition engine, methane, dual fuel system, combustion process.
\end{abstract}

\section{Introduction}

Increasing the share of renewable fuels in the overall energy balance is one of the basic directions of studies on modern combustion engines. This is connected not only with the dwindling resources of fossil fuels, but also with the fight against global warming. These actions are supported not only by governments, but by international organizations as well. The goal adopted by the European Union is to produce $20 \%$ of energy from renewable energy sources by 2020 [6].

Meeting these targets requires not only intensification of the search for new raw materials and technologies for obtaining fuels, but also the development of more efficient technologies for converting the energy contained in fuel to electric or mechanical energy.

Biogas is a potential fuel whose share in the overall energy balance will be rising in the nearest future. This gas can be obtained both by processing energy raw materials of different kinds, e.g. biomass, and also forms spontaneously as a result of phenomena occurring in nature, e.g. in dumping sites or sewage treatment plants. The chemical composition of biogas is not constant and depends not only on the raw materials from which it is produced, but also on the used technology. The approximate composition of biogas obtained from different sources is presented in Table 1. It is also important to stress that the use of these fuels for energy purposes reduces the emission of methane spontaneously released from, among others, 
dumping sites, which is ca. 25 times more harmful to the ozone layer than carbon dioxide [7].

The main combustible biogas component is methane, whose content ranges from $40-80 \%$, the remaining part of biogas is made up of non-combustible components which are the ballast, among which carbon dioxide has the highest percentage, its content can reach 55\%. New biogas purification technologies currently exist which can raise the methane percentage in gas to over $95 \%$, so purified biogas is called biomethane. This solution forces biomethane into the natural gas transmission grid, which is extremely beneficial because it allows using the existing gas grid to send fuel and to feed temporary fuel surpluses or into the grid supplement fuel with natural gas during moments of shortage. It should, however, be remembered that this solution is quite expensive due to the substantial cost of biogas purification $[1,4,5,6]$.

Because of the high octane number of methane (over 100), both biogas and biomethane can be directly used for fuelling spark-ignition engines. In this solution, engine adaptation for this fuel is practically unnecessary. When methane is used to fuel the much more efficient compression-ignition engines, it is necessary to adapt the engine for operation with this fuel.

To maintain the high compression ratio of the compression-ignition engine for a higher overall efficiency of the engine, it is necessary to use a dual-fuel system. The reason is the relatively high methane autoignition temperature, ca. $630{ }^{\circ} \mathrm{C}$. In the dual-fuel system, a mixture of gaseous fuel with air is inducted into the engine combustion chamber and a small liquid fuel charge called the pilot charge, whose task is to cause autoignition, is injected towards the end of the compression stroke $[1,3,4,6]$.

Table 1. Volumetric content of individual components in gaseous fuels [7]

\begin{tabular}{|l|c|c|c|c|c|}
\hline \multicolumn{1}{|c|}{ Gaseous fuel } & $\begin{array}{c}\mathrm{H}_{2} \\
{[\%]}\end{array}$ & $\begin{array}{c}\mathrm{CH}_{4} \\
{[\%]}\end{array}$ & $\begin{array}{c}\mathrm{CO}_{2} \\
{[\%]}\end{array}$ & $\begin{array}{c}\mathrm{N}_{2} \\
{[\%]}\end{array}$ & $\begin{array}{c}\mathrm{O}_{2} \\
{[\%]}\end{array}$ \\
\hline Agricultural biogas & - & $45-75$ & $25-55$ & $0-5$ & $0-3$ \\
\hline $\begin{array}{l}\text { Biogas from sewage treatment } \\
\text { plants }\end{array}$ & - & $57-62$ & $33-38$ & $3-8$ & $0-1$ \\
\hline Landfill gas & $0-15$ & $37-67$ & $24-40$ & $10-25$ & $0-45$ \\
\hline Mine gases & - & $40-80$ & $8-15$ & $20-40$ & $0-10$ \\
\hline
\end{tabular}

\section{Effect of biogas composition on the properties of the combustible mixture}

Biogas composition has a decisive effect on engine operating efficiency. This is connected not only with the calorific value of fuel, but also with the changed properties of the combustible air/gaseous fuel mixture. Since gaseous fuel has a much higher volume than liquid fuel, the air volume available in the combustion chamber decreases considerably. The obtainable engine power is limited by the air volume available in the combustion chamber. When liquid fuels are used, the whole combustion chamber volume can be filled with fresh air and, in this case, the liquid fuel volume is negligibly low. For gaseous fuels, the fuel 
volume is already substantial and affects significantly combustion chamber fresh air filling.

The degree of combustion chamber air filling $\gamma_{\text {air }}$ can be used to determine the air volume inducted into the combustion chamber with the air/gas mixture. With the assumption that the cylinder filling efficiency is $\lambda_{v}=1$, complete exhaust gas removal from the combustion chamber and air/gas mixture formation outside the combustion chamber, this coefficient can be written as [6]:

$$
\gamma_{\text {air }}=\frac{V_{\text {air }}}{V_{c h}}=\frac{V_{c h}-V_{\text {fuel }}}{V_{c h}}
$$

where:

$V_{\text {air }}$ - air volume in the air/gas mixture;

$V_{c h}$ - combustion chamber volume;

$V_{\text {fuel }}$ - gaseous fuel volume.

Changes in the degree of combustion chamber air filling $\gamma_{\text {air }}$ for an engine operating on an air/gaseous fuel mixture (e.g. biogas) depending on the percentage of $\mathrm{CH}_{4}$ in the fuel with different excess air coefficients are shown in Fig. 1.

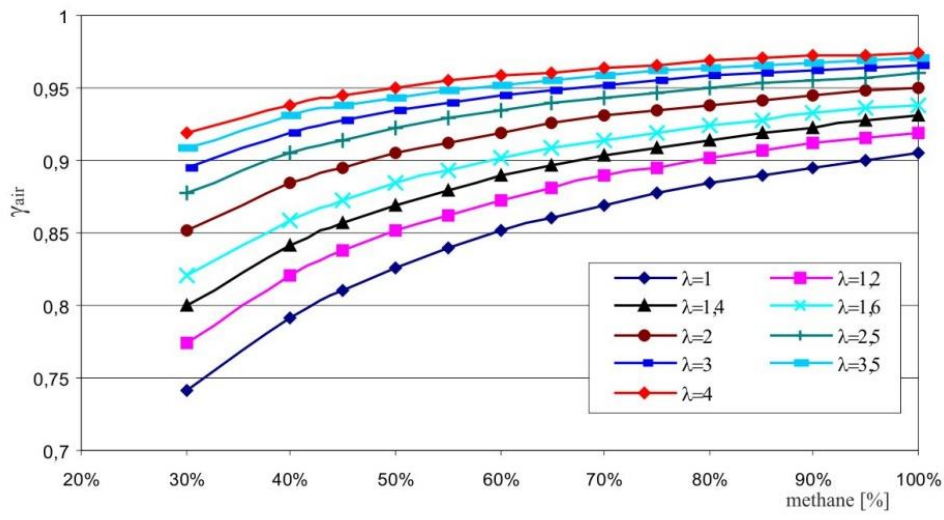

Fig. 1. Changes in the combustion chamber air filling coefficient depending on the biogas methane content with different $\lambda$ coefficients [6]

It can be concluded, based on the changes in combustion chamber air filling, that an increase in the percentage of methane in fuel significantly affects combustion chamber use. For fuels with ca. $40 \%$ methane content, the degree of engine combustion chamber volume use is below $80 \%$. 


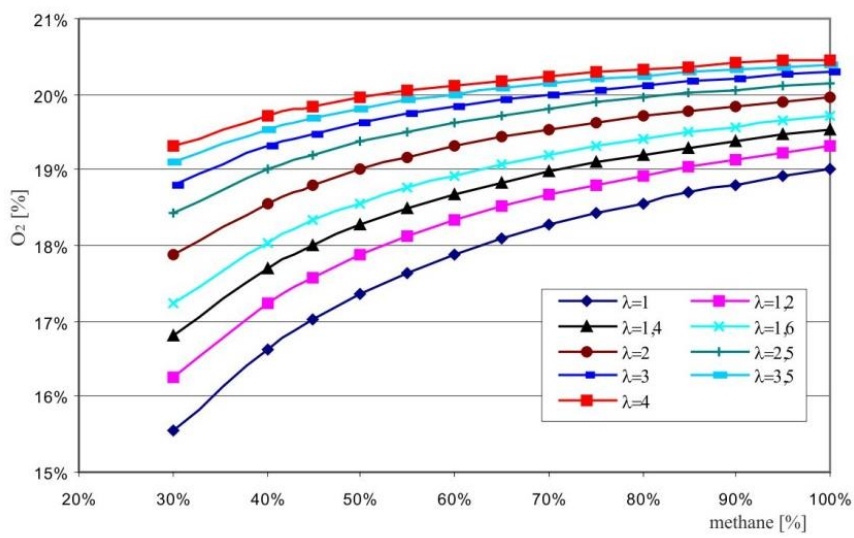

Fig. 2. Change in oxygen concentration in the fuel/air mixture depending on the biogas methane content with different $\lambda$ coefficients [6]

Because the gaseous fuel volume is substantial, oxygen concentration in the air/gaseous fuel mixture changes, which affects the course of the combustion process. Fig. 2 shows the change in the oxygen content in the mixture depending on biogas composition and the excess air coefficient $\lambda$. Fig. 3 shows the change in the calorific value of the air/biogas mixture depending on the methane content and the excess air coefficient $\lambda$.

The relationships presented above clearly show the substantial effect of biogas composition on chamber fresh air filling, which affects the acceptable amount of burnable fuel. Oxygen concentration in the mixture also changes, which affects the fuel combustion rate. The calorific value of the mixture also changes significantly, which determines the obtainable power.

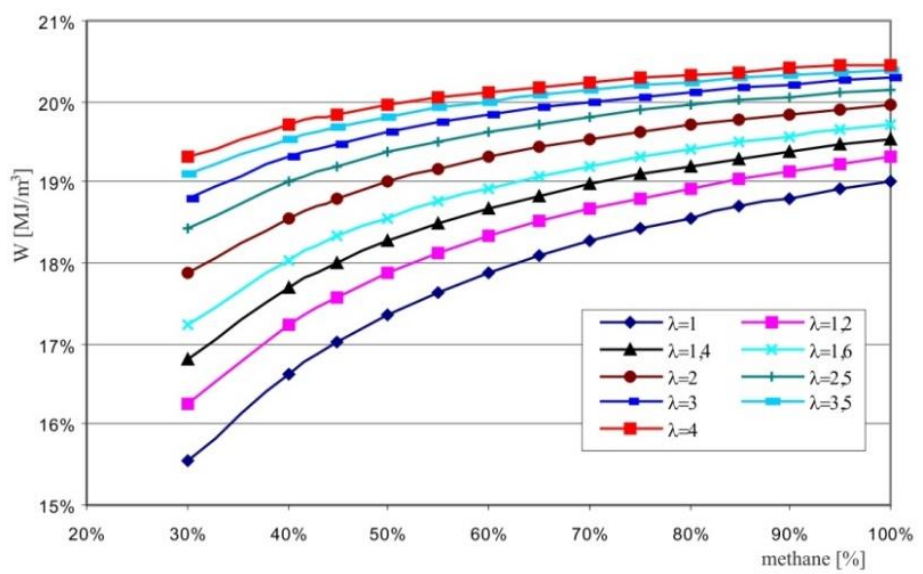

Fig. 3. Change in the calorific value of $1 \mathrm{~m}^{3}$ of the air/biogas mixture depending on the methane content with different $\lambda$ coefficients [6]

All of the presented coefficients depend on the biogas methane content, which entails a lower amount of non-combustible gases which do not participate in 
combustion. Improved values of the analyzed indices can be obtained by increasing the excess air coefficient, but it should be remembered that by increasing this coefficient, we change the methane combustion parameters (conditions), which has a substantial effect not only on the course of the combustion process, but also on engine operating efficiency. It should be realized that below the lower flammability limit the air/methane mixture becomes non-combustible, which practically prevents flame movement in the engine combustion chamber. In this case, only the part of the mixture within the injected liquid fuel stream burns in a dual-fuel engine. It is therefore extremely important to properly select the size of the pilot charge, the degree of its atomization in the combustion chamber (pilot charge injection pressure) and also its injection advance angle.

\section{Test stand}

To determine the effect of individual liquid fuel pilot charge parameters on the operating efficiency of a dual-fuel compression-ignition engine, a test stand was built allowing free regulation of the size and composition of the gaseous fuel charge as well as the injection of a pilot charge with the adopted parameters.

A Yanmar L100N6 single-cylinder compression-ignition engine was used for the tests and the basic data of this engine is compiled in Table 2.

Table 2. Basic technical parameters of the Yanmar engine

\begin{tabular}{|l|c|}
\hline Engine type & L100N6CA1T1CAID \\
\hline Displacement & $534 \mathrm{~cm}^{3}$ \\
\hline Compression ratio & 20 \\
\hline Piston stroke/diameter & $86 / 75 \mathrm{~mm}$ \\
\hline Max power & $7.4 \mathrm{~kW}$ \\
\hline Max torque & $27 \mathrm{Nm}$ \\
\hline Max speed & $3600 \mathrm{~min}^{-1}$ \\
\hline Injection type & direct \\
\hline Cooling system & air cooling \\
\hline
\end{tabular}

The original mechanical fuel system of the tested engine was replaced with a laboratory common rail fuel system controlled from the level of a PC application (Fig. 4.) [7]. The used system allowed free regulation of the following system operation parameters:

- common rail fuel pressure value;

- fuel charge size, adjusted by the injector opening time with an accuracy of $1 \mu \mathrm{s}$;

- fuel injection advance angle, adjusted every $0.35^{\circ} \mathrm{CA}$;

- the possibility of free regulation of the voltage and current changes at the injector coil.

To ensure that a methane/carbon dioxide mixture with the adopted proportions is fed to the engine, a preparation system was developed for this mixture. Both methane and carbon dioxide were fed from cylinders containing 
these gases. After the pressure was reduced by pressure regulators, the gases were fed to mass flow controllers, which were responsible for adjusting the flow rate of individual gases. The gases were then fed to a special mixing chamber, where they were mixed with air fed to the engine (Fig. 4). An application operated from the PC level was used to control the flow rate of the gases [7].

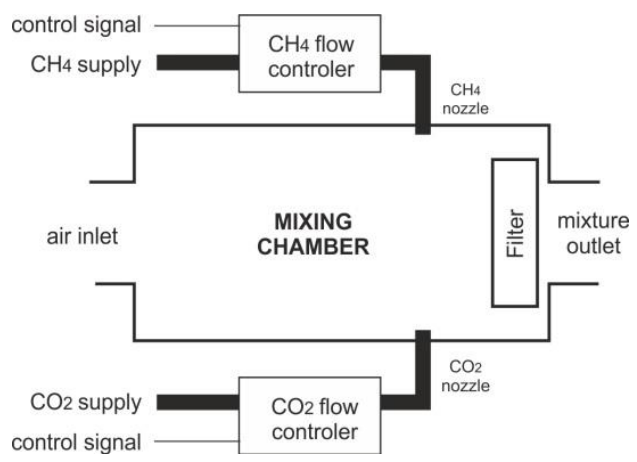

Fig. 4. System of preparing of gas mixture

The tested engine was mounted on an Automex AMX211 engine test bed. The used test bed allows, among others, stabilization of engine revolutions, which considerably facilitates tests on engines under defined conditions. The test bed is controlled by an individual operator panel. However, because of test bed controller communication with the operator panel by a CAN network (Controller Area Network), it is possible to control brake operation from the level of a PC application. The view of the complete test stand is shown in Fig. 5.

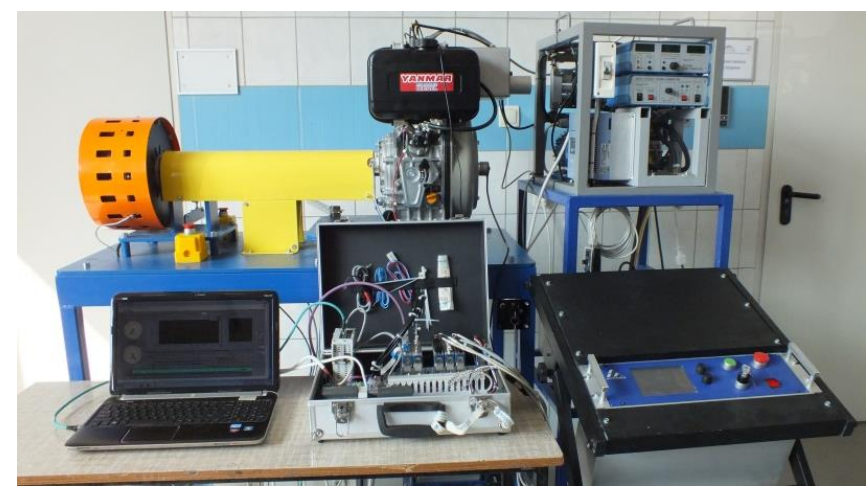

Fig. 5. Test stand view

A special application was developed in LabVIEW to integrate the control of individual engine fuel systems and test bed operation. A cRIO controller allowing realtime operation was used for control. Available extension cards for the applied controller were used to control individual systems. A block diagram of the developed control system is shown in Fig. 6. 


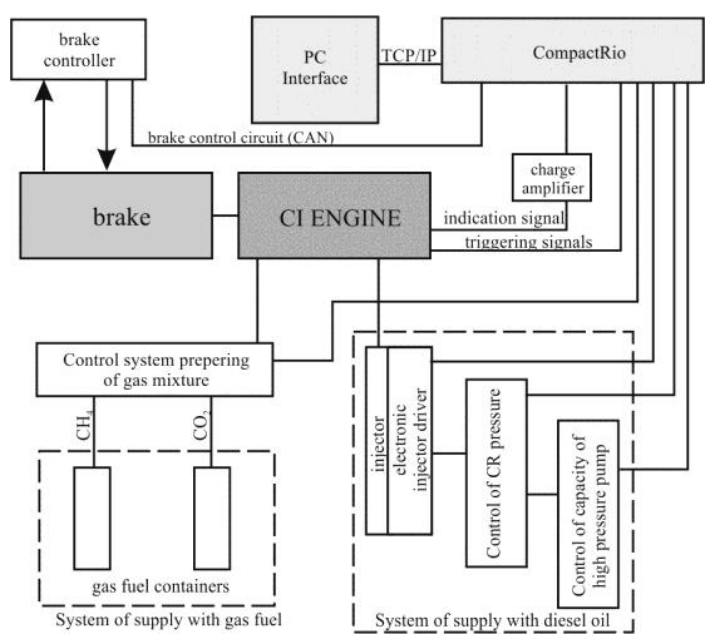

Fig. 6. Scheme of control system

\section{Test results and their analysis}

One of the basic control parameters of a compression-ignition engine is the fuel injection advance angle. This angle has a decisive effect on the course of the fuel combustion process in the combustion chamber, which determines the course of heat release in the combustion chamber. This affects not only engine power, but also the level of toxic compound emission into the atmosphere.

The selection of the proper ignition advance angle is particularly important for dual-fuel compression-ignition engines. In the classical modern electronically controlled compression-ignition engine, the fuel charge is divided into several parts: a small pilot charge is first injected to prepare the combustion chamber for burning the main fuel charge. Since for dual-fuel compression-ignition engines, pilot charge injection results in the ignition of the air/gas mixture, the injection of the first (even small) liquid fuel charge initiates the ignition of the gaseous fuel charge proper. This considerably hinders the control of combustion in the engine. The selection of the proper ignition advance angle for this engine is therefore extremely important.

The tests described below determined the effect of the diesel fuel pilot charge injection advance angle on the engine operating parameters. The injection advance angle of the liquid fuel charge was changed during the tests for a constant liquid fuel charge and a constant size and composition of the gaseous fuel charge. The tests were conducted at a constant speed, maintained by the brake at $3,000 \mathrm{rpm}$. The percentage proportions of gaseous fuel to liquid fuel were changed during the tests. The tests were conducted for different diesel fuel pilot charge sizes and different gaseous fuel composition. Example changes in the engine torque depending on the liquid fuel injection advance angle for different gaseous fuel compositions and different fuel proportions are shown in Fig. 7-9. Fig. 10 shows 
the changes in engine efficiency for different fuel proportions when using gaseous fuel with a $66 \% \mathrm{CNG}$ content.

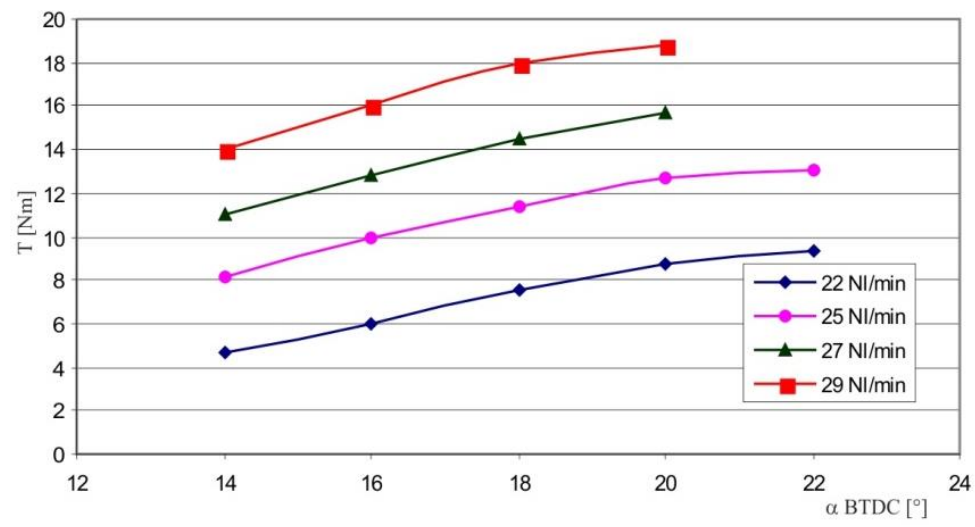

Fig. 7. Effect of the injection advance angle on the engine torque for a constant diesel fuel charge of $3 \mathrm{~mm}^{3}$ and variable charges of gas containing 100\% CNG, ( $\mathrm{Nl}$ - normal liters gas volume under normal conditions: pressure $1013.25 \mathrm{hPa}$ and gas temperature $273.16^{\circ} \mathrm{K}$ )

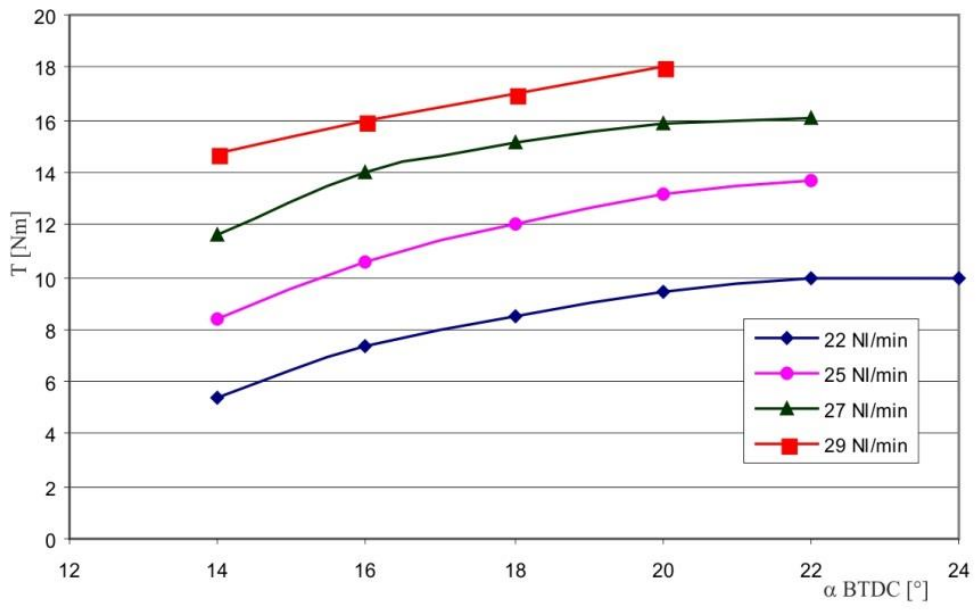

Fig. 8. Effect of the injection advance angle on the engine torque for a constant diesel fuel charge of $3 \mathrm{~mm}^{3}$ and variable charges of gas containing $66 \% \mathrm{CNG}$ 


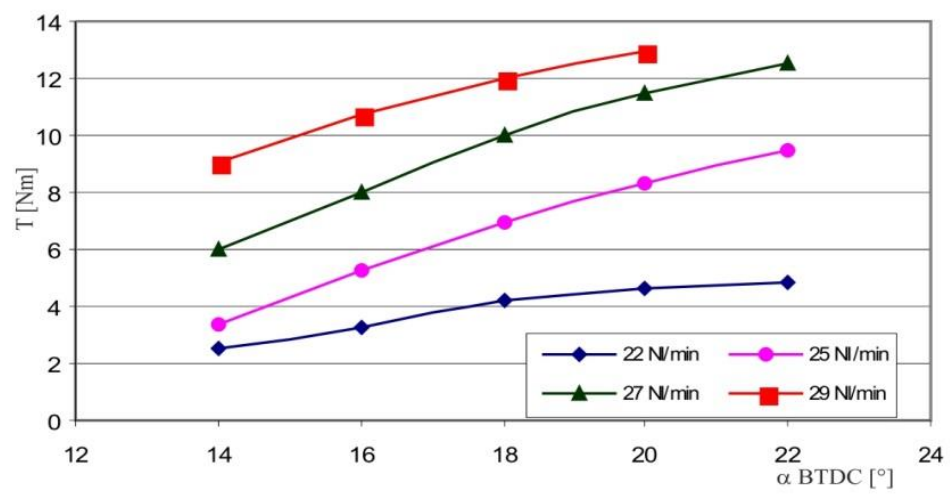

Fig. 9. Effect of the injection advance angle on the engine torque for a constant diesel fuel charge of $3 \mathrm{~mm}^{3}$ and variable charges of gas containing $50 \% \mathrm{CNG}$

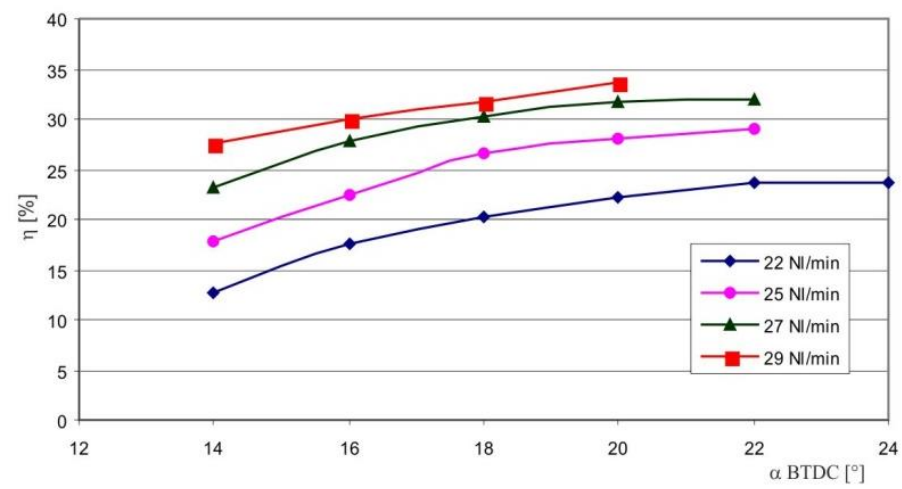

Fig. 10. Effect of the injection advance angle on engine efficiency for a constant diesel fuel charge of $3 \mathrm{~mm}^{3}$ and variable charges of gas containing $66 \% \mathrm{CNG}$

\section{Summary}

It should be clearly stressed that the fuel injection advance angle values shown in Fig. 7-10 refer to the values of the angle measured between the moment of control pulse feeding to the electromagnetic injector and the engine TDC. The real moment of fuel charge injection into the engine combustion chamber is delayed.

The results presented above clearly show the importance of diesel fuel pilot charge injection advance angle selection for engine performance. With an increasing value of this angle at a constant engine speed, the engine torque rises. The maximum value of the liquid fuel charge injection advance angle depends on the proportion of individual fuels in the combustion chamber because the speed of flame propagation changes with an increasing percentage of gaseous fuel in the 
combustible mixture. Therefore, it is necessary to use lower pilot charge injection advance angles for higher gaseous fuel percentages.

Analyzing the changes in overall engine efficiency, it can be observed that its value rises not only with an increasing pilot charge injection advance angle, but also with an increasing percentage of methane in the whole fuel charge. This is mostly due to the changing methane/air proportion. At lower methane concentrations, the mixture is too lean and not the whole mixture is combusted, but only its part within the liquid fuel stream.

The presented results confirm the significant effect of the fuel charge injection advance angle on engine performance. The results show that the methane concentration in the mixture is also extremely important - with leaner mixtures, the gaseous fuel charge is not fully combusted, which not only impairs engine efficiency, but also causes an increase in the emission of unburnt hydrocarbons into the atmosphere. A possible method for improving methane combustion in this engine would be the introduction of air throttling to control the excess air coefficient and maintain it at the required level.

\section{References}

1. Azimov U., Tomita E., Kawahara N., Dol S.S. 2012. Combustion characteristics of syngas and natural gas in micro-pilot ignited dual-fuel engine. World Academy of Science, Engineering and Technology, 72, 1618-1625.

2. Korakianitis T., Namasivayam A.M., Crookes R.J. 2011. Diesel and rapeseed methyl ester (RME) pilot fuels for hydrogen and natural gas dual-fuel combustion in compression-ignition engines. Fuel, 9, 2384-2395.

3. Makareviciene V., Sendzikiene E., Pukalskas S., Rimkus A., Vegneris R. 2013. Performance and emission characteristics of biogas used in diesel engine operation. Energy Conversion and Management, 75, 224-233.

4. Ray N.H.S., Mohanty M.K., Mohanty R.C. 2013. Biogas as alternate fuel in diesel engines: A literature review. Journal of Mechanical and Civil Engineering, 9(1), 23-28.

5. Ray N.H.S., Mohanty M.K., Mohanty R.C. 2013. A Study on application of biogas as fuel in compression ignition engines. International Journal of Innovations in Engineering and Technology (IJIET), 3(1), 239-245.

6. Wierzbicki S. 2012. Biogas as a fuel for diesel engines. Journal of KONES, 19(3), 477-482.

7. Wierzbicki S., Śmieja M. 2014. Visualization of the parameters and changes of signals controlling the operation of common rail injectors. Solid State Phenomena, 210, 136-141. 